\title{
ESCRITA FEMININA E MILITÂNCIA NO BRASIL MERIDIONAL: JULIETA DE MELO MONTEIRO E DUAS DE SUAS BANDEIRAS DE LUTA (ABOLICIONISTA E FEDERALISTA)
}

\author{
WOMEN'S WRITING AND ACTIVISM IN SOUTHERN BRAZIL: \\ JULIETA DE MELO MONTEIRO AND TWO OF HER STRUGLE FLAGS \\ (ABOLICIONIST AND FEDERALIST)
}

DOI 10.20873/uft2179-3948.2021v12n1p72-85

\author{
Francisco das Neves Alves ${ }^{1}$ \\ Isabel Maria da Cruz Lousada ${ }^{2}$
}

\begin{abstract}
Resumo: Ao longo do século XIX e nos primeiros decénios do seguinte, houve um incremento na produção literária vinculada à escrita feminina. Desenvolvendo abordagens e estilos próprios, as mulheres seguiram o caminho das letras, vencendo os significativos obstáculos que lhes foram impostos. Em certos casos, lançando mão do seu reconhecimento intelectual, tais escritoras também optaram pela prática de uma militância, não só no campo literário, mas também no socioeconómico, no político-ideológico e no cultural. Este ensaio aborda um desses casos, representado por Julieta de Melo Monteiro, escritora sul-rio-grandense que conquistou prestígio a partir da sua luta pela emancipação feminina, mas que também levantou a bandeira de engajamento em nome de outras duas causas - a abolição da escravatura e a resistência a um regime ditatorial.
\end{abstract}

Palavras-chave: Escrita feminina; Militância; Julieta Monteiro; Brasil meridional.

\begin{abstract}
Throughout the 19th century and in the first decades of the following, there was an increase in literary production entailed to female writing. Women followed the path of letters developing their own approaches and styles, overcoming the significant obstacles imposed on them. Sometimes, using their intellectual recognition, these writers also opted for the practice of activism, not only in the literary field, but also in the socioeconomic, political-ideological and cultural fields. This essay addresses one of these cases, represented by Julieta de Melo Monteiro, a writer from Rio Grande do Sul who gained prestige from her struggle for female emancipation, and who also raised the flag of engagement in the name of two other causes - the abolition of slavery and resistance to a dictatorial regime.
\end{abstract}

Keywords: Female writing; Activism; Julieta Monteiro; Southern Brazil.

\footnotetext{
${ }^{1}$ Universidade Federal do Rio Grande (FURG). E-mail: franciscodasnevesalves@ gmail.com

${ }^{2}$ Investigadora do NOVAFCSH - CICS.NOVA - Centro Interdisciplinar de Ciências Sociais da Universidade

Nova de Lisboa. E-mail: isabel.lousada@fcsh.unl.pt
} 
O contexto literário do século XIX e as primeiras décadas da centúria seguinte foram marcados por amplo predomínio de escritores do sexo masculino. Entretanto, enfrentando todo o tipo de preconceito e até de resistência, diversas mulheres lançaram-se no caminho das letras, difundindo os seus escritos através de livros e da imprensa periódica. A produção textual de autoria feminina distingue-se de outros textos por possuir um tom, uma dicção, um ritmo e uma respiração próprios, com uma plena articulação entre uma escrita intimista e as reflexões diante da realidade (BRANCO, 1991, p.13-14). Na escrita feminina podem ser identificadas tanto as indagações, os desejos reprimidos ou incontroláveis e a batida sufocada ou desenfreada dos corações (BRANCO, 1989, p.87), quanto os olhares reflexivos sobre a sociedade nas quais as escritoras estavam inseridas, de maneira que, nos textos literários de autoria feminina podem surgir algumas marcas específicas ou rastros de subjetividade (MAGALHÃES, 2005, p. 9) os quais interagem com a conjuntura que os cerca.

A escrita feminina pode trazer em si a identificação de características literárias próprias, ou seja, as obras de autoria feminina podem apresentar "qualidades", em sentido neutro, próprias, as quais aparecem tão diversificadas quanto as encontradas entre obras de homens escritores. Nessa linha, ocorre a possibilidade de que sejam detectados alguns traços comuns, detonadores de afinidades, ou de um denominador comum, para além das múltiplas diferenças (MAGALHÃES, 1995, p. 17). Tratando-se da transição do século XIX para o XX, há uma tendência de julgar que tais características intrínsecas da escrita feminina fossem mais evidentes, tendo em vista a condição social imposta à mulher, criando-lhe significativos obstáculos que se antepuseram constantemente à sua ação. Desse modo a produção textual feminina, em suas peculiaridades ou similitudes está fortemente vinculada aos contextos histórico-culturais e sociais específicos em que foi elaborada, ou seja, como fenómeno histórico que é, tal escrita não fica intocada pelo devir histórico (MINGOCHO, 2005, p. 8).

Nas suas ações como intelectuais e articuladas com a conjuntura histórica vivenciada, essas mulheres escritoras, muitas vezes, considerando o reconhecimento conquistado, levaram em conta tal prestígio para defender determinadas causas, desfraldando bandeiras de batalha em prol de tais ideias. Assim, junto das suas carreiras literárias, tais intelectuais atuavam como escritoras e jornalistas engajadas em certas militâncias, uma vez que a hierarquia de intelectual também foi utilizada como uma estratégia nas lutas, pois a notoriedade no campo da cultura ficava inter-relacionada com o embate político. Nesse sentido, as suas ações poderiam ser compreendidas inteiramente se recolocadas no campo ideológico de que faziam parte, o qual exprimia, de uma forma mais ou menos transfigurada, a posição de uma categoria particular de 
escritores na estrutura do campo intelectual, por sua vez incluído em um tipo específico de campo político. Nessa linha, em meio ao processo literário-cultural, estabelecia-se um corpus constituído no interior do campo ideológico, o qual se inseria em um sistema de relações de concorrência e de conflito entre grupos situados em posições diferentes no interior de um campo intelectual. Este, por sua vez, também ocupava uma dada posição no campo do poder (BOURDIEU, 2007, p. 184 e 186).

Tal intelectualidade coloca-se em condições de intervir em outros campos de atuação, em nome da autonomia e dos valores específicos de um campo de produção cultural que chegou a um alto nível de independência em relação aos demais poderes. Nessa linha, o intelectual torna-se um ser paradoxal, a partir da alternativa entre autonomia e engajamento, uma vez que a sua existência se dá, historicamente, na e pela superação dessa oposição. Além disso, ele é uma personagem bidimensional, que não existe e não subsiste como tal a não ser que (e apenas se) esteja investido de uma autoridade específica, a qual é conferida por um mundo intelectual autónomo. Em tal contexto, ele age até mesmo com certa autonomia em relação aos poderes religiosos, políticos e económicos (BOURDIEU, 1996, p. 150 e 370).

De acordo com tal perspectiva, torna-se fundamental a representação que os intelectuais possuem do mundo social e a função por eles desempenhada nesse mesmo mundo. A meta essencial é o convencimento do público, uma vez que o campo intelectual está incluso em um campo de poder, implicando em um habitus socialmente constituído, o qual possibilita ao intelectual ocupar as posições que lhe eram oferecidas por um determinado estado do campo intelectual, bem como adotar as tomadas de posição estéticas ou ideológicas vinculadas a tais posições (BOURDIEU, 2007, p. 185, 188 e 190).

Essa ação social do intelectual reflete-se essencialmente por meio da sua produção bibliográfica e, mormente, por meio das páginas da imprensa. Nessa época, escrever nos periódicos era uma ocupação reservada a literatos que entendiam os jornais e as revistas como espaços públicos de opinião, de maneira que tal ato constituía uma forma de afirmação de uma autoridade, um modo de publicar ideias, de divulgar obras, ou ainda, de defender ideologias, de travar polémicas diversas, enfim, de participar ativamente na construção da esfera pública (PEIXINHO, 2010, p. 427). Ocorria, assim, uma inter-relação entre o campo jornalístico e os campos de produção cultural, por meio de uma intervenção de produtores culturais situados em um lugar incerto entre o campo jornalístico e os campos especializados. Dessa forma, esses “intelectuais-jornalistas" passavam a servir-se do seu duplo vínculo para esquivar as exigências específicas dos dois universos e para introduzir em cada um deles poderes mais ou menos bem 
adquiridos no outro, ficando em condições de exercer dois efeitos principais, ou seja, promover formas novas de produção cultural e fazer valer seus julgamentos críticos e princípios de avaliação, ratificados a partir de uma suposta autoridade intelectual (BOURDIEU, 1997, p. 111).

Tal ação militante promovida a partir da escrita feminina teve destaque também no Brasil Meridional, onde diversas mulheres se dedicaram às letras e manifestaram engajamentos a favor de determinadas bandeiras. Nessa conjuntura, uma das autoras de maior destaque na promoção da escritura e da leitura de natureza feminina foi Julieta de Melo Monteiro. Ela nasceu e viveu no Rio Grande do Sul, entre 21 de outubro de 1855 e 27 de janeiro de 1928, dedicando a sua vida à literatura e ao jornalismo. Com a sua ação múltipla, trilhou os caminhos da poesia, da crónica, do conto e da dramaturgia, além de uma longeva carreira como professora. Porém, foi nas atividades jornalísticas que ocorreu a sua atuação mais destacada, compondo o quadro de colaboradoras de vários periódicos, dos mais diversos géneros, no âmbito regional, nacional e internacional. Além disso, no final dos anos 1870, foi editora/proprietária da Violeta, uma das folhas precursoras em termos de imprensa feminina no contexto sul-rio-grandense e, desde 1883, dirigiu com a sua irmã Revocata Heloísa de Melo, o Corimbo, um dos mais importantes representantes brasileiros do jornalismo de cunho feminino (COELHO, 2002, p. 314; FLORES, 1999, p. 350-351; SCHMIDT, 2000, p. 306-319; SCHUMAHER \& BRAZIL, 2000, p. 308; e SOARES, 1980, p. 145-146).

Além da participação em várias folhas literárias, noticiosas, ilustradas e humorísticas e do trabalho incessante na Violeta e no Corimbo, onde permaneceu até a morte, Julieta publicou os livros Prelúdios (1881), Oscilantes (1891), Coração de mãe (1893), Alma e coração (1897), Berilos (1911) e Terra Sáfara (1928 - edição póstuma). Dentre as causas defendidas pela escritora por meio das páginas dos jornais e dos livros, a de maior destaque e pela qual ela ficou mais conhecida foi aquela em nome da emancipação feminina, lutando por um novo papel social da mulher, mais igualitário e participativo, o qual seria obtido a partir do aprofundamento da educação. Mas Julieta Monteiro travou pelo menos outras duas relevantes lutas. Uma delas deu-se a partir da promoção do ideário abolicionista, denunciando as mazelas das práticas escravistas no Brasil e conclamando uma perene campanha pela extinção da estrutura escravocrata. Outra bandeira sustentada pela autora foi a da liberdade contra o regime autoritário que dominou o Rio Grande do Sul durante toda a República Velha, de modo que Julieta militou ao lado da oposição federalista, contra o modelo ditatorial, centralista, personalista e exclusivista, preeminente por décadas em meio à sociedade sulina. 


\section{A abolicionista}

As páginas impressas tiveram significativa função como elemento propagador das ideias e práticas abolicionistas, em uma época em que se tornou uma prática corrente a colocação em dúvida, bem como os atos de analisar e combater a pretensa sacralidade das instituições, entre elas, a escravidão, a monarquia e o latifúndio (SODRÉ, 1966, p. 268). Desse modo, o papel desempenhado pela intelectualidade na chamada questão servil foi tão fundamental que a dinâmica da mesma passou a depender basicamente do debate a serviço ou crítica da causa, levando à mobilização da sociedade civil (RÜDIGER, 1993, p. 28-29). Assim, textos polémicos, artigos e livros apareciam em profusão promovendo o pensamento antiescravista que se desenvolvia crescentemente (QUEIROZ, 1981, p. 55).

Predominantemente, o pensamento abolicionista expresso a partir da intelectualidade refletia a ideia da luta pelo progresso e pela grandeza da nação, a partir da qual a abolição representava a destruição do passado, e conceitos como os de pátria, civilização e integração do país, no concerto das nações ditas livres e civilizadas, sobressaiam (CARDOSO, 1991, p. 213). A abolição representava, de acordo com essa perspectiva, a vitória do novo sobre o velho, do moderno em relação ao anacrónico. Nesse sentido, considerava-se que ser a favor da emancipação dos escravos equivaleria a ser a favor do progresso e da civilização, uma vez que a escravidão fora condenada em nome desses mesmos fundamentos nos países mais desenvolvidos (COSTA, 1988, p. 63).

Julieta de Melo Monteiro desenvolveu amplas empreitadas para erradicação da pobreza e, no campo social, promoveu ainda várias campanhas favoráveis ao abolicionismo. Além das ações práticas em prol da abolição, como a arrecadação de fundos para promover alforrias e a fundação de núcleos emancipacionistas, a escritora destinou alguns de seus escritos para denunciar as mazelas da escravidão. Um pressuposto fundamental proposto pela autora foi calcado no ato da denúncia quanto aos descalabros e os atos de desumanidade associados à escravidão. A maior parte dos textos de cunho abolicionista da lavra de Julieta foi elaborada na década de 1880 e publicada nas páginas do Corimbo e do livro Oscilantes, que, apesar de editado em 1891, também reunia produções escritas em época anterior à erradicação da escravidão.

No Corimbo, poucos meses antes da abolição, a escritora publicou "A emancipação no Rio Grande do Sul", texto no qual afirmava que a "gloriosa província" sulina agitava-se "fremente ao brado de liberdade completa". Segundo ela, "há muito que os rio-grandenses 
mostram o seu amor à santa causa da abolição dos cativos" e, "vibrantes" vinham se erguendo “em bem desta nobre cruzada". Qualificava o escravismo como um "ignominioso cativeiro", defendendo a necessidade de romper-se "as espessas trevas em que jazem esses infelizes", desejando que viesse a aparecer-lhes "o tão almejado sol da liberdade". Nessa linha, Julieta Monteiro exortava os rio-grandenses a lavar "do fértil terreno" nacional "a nódoa infame que o desonra", devendo todos hastear "a bandeira sacrossanta dos livres", em atitude "digna de ser recordada e festejada pelos pósteros”. Ainda em tom de conclamação, ela saudava aqueles que trabalhavam "sem tréguas em favor de tão caridoso fim" e aplaudia "aos que plenos de satisfação, mostrando a grandeza de sua alma", se apressavam em "quebrar jubilosos as algemas que roxeiam os pulsos dos escravizados" (CORIMBO, Rio Grande, out.1887, a. 3, n. 27, p. 4).

Uma das incursões de Julieta Monteiro no tocante à questão da escravidão ocorreu por meio de versos que encerravam o soneto "Cena do lar", o qual reconstruía o cenário de um ambiente familiar, no qual parecia prevalecer uma certa alegria ou, ao menos, harmonia, na convivência entre a filha e seus pais, sem faltar até mesmo a figura do animal de estimação. Como em tantas outras composições da poetisa, o âmbito familiar era muitas vezes matizado a partir de uma idealização. Entretanto, a conclusão do poema mostrava um olhar que destoava do todo, pois, ao longe, visto através de uma janela e, portanto, apartado daquele conjunto de certo modo feliz, estava a imagem de um "pobre escravo" que, "merencório e cansado" e sobrecarregado pelos exageros de seus trabalhos forçados, expressava suas tristezas e infortúnios por meio de uma melancólica canção (MONTEIRO, 1891, p. 53).

Em outra composição, denominada "Cena do cativeiro", a intelectual agia mais diretamente como militante abolicionista, denunciando a enorme carga de injustiça que cercava o regime escravocrata. Tal como vários dos representantes da intelectualidade que agiram em prol do abolicionismo, Julieta procurava demonstrar o quão absurda era aquela instituição que permitia a propriedade de um ser humano sobre outro, com direito de vida e morte daquele sobre este. A crítica centrava-se nas práticas dos castigos físicos infligidos aos escravos, no caso específico a uma mulata, cujo "crime" teria sido atender o filho às portas da morte. A poetisa mostrava o escravista como um indivíduo irascível, sem nenhum tipo de comiseração, pois não cedera nem aos apelos da própria filha em favor da escrava. Ficava evidenciada a intenção da escritora em denunciar as excrecências da escravidão, caracterizada pela crueldade do senhor de escravos, chamado de "verdugo" e "harpia", ao impor à cativa um "castigo vil" Por outro lado, Julieta lembrava que a escrava era um ser humano e, mais do que isso, uma “mulher-mãe”, que não poderia receber aquele tipo de tratamento (MONTEIRO, 1891, p. 119). 
Sob o título de "Anelo", a poetisa criticava a instituição escravista, qualificando-a como um dos piores males que assolava sua terra natal. Ela demonstrava que o seu maior anseio, o seu desejo mais ardente e, enfim, a sua maior aspiração era ver o fim da escravidão. O seu pensamento alinhava-se às teorias abolicionistas que consideravam o escravismo como um fator anacrónico que só trazia uma visão negativa para com o Brasil, denegrindo os seus progressos a partir da continuidade daquela prática. Para a autora, a escravidão feria princípios básicos vinculados à humanidade e à civilização, de acordo com os padrões então vigentes, de modo que, reproduzindo os dizeres de muitos dos abolicionistas da época, a extinção dos princípios escravocratas não traria apenas a libertação dos escravos, mas do país como um todo. Nesse sentido, ela imaginava que no "formoso pendão da nossa terra", deveria ocorrer o "fim da nódoa denegrida", surgindo "a liberdade apetecida". Propunha que se extinguisse "esse terror que nos mancha e nos aterra", o qual não deveria "perdurar, ter maior vida" e conclamava por um novo tempo com o fim da "opressão" e o nascer do "sol da liberdade", eliminando aquele "lutulento vulto do passado" (MONTEIRO, 1891, p. 122).

Bem de acordo com o ideário liberal, que orientou suas ações de militância política e ideológica, Julieta Monteiro aplaudiria efusivamente a Lei Áurea de 13 de maio de 1888, a qual promovia a extinção definitiva da instituição escravista no Brasil. Isso ocorreu através do soneto "Liberdade", editado nas páginas de Oscilantes, no qual a escritora praticamente criava uma alegoria poética para registar aquele momento histórico:

Entre lençóis de espuma vaporosa,

Ao som da Marselhesa sem rival,

Em manhã de verão, fresca e formosa,

Num peregrino berço de coral;

Quando o sol deslumbrante e sorridente

Surgindo no seu carro majestoso,

Mirava a fronte em lago alvinitente

Onde brincava um cisne gracioso;

E a terra inteira ouvindo o alegre canto

Mais belo que o sonhar da mocidade,

Sentia em si suave e doce encanto;

De uma santa mulher, a - Caridade,

Que enxuga sempre aos mártires o pranto,

Nasceu pura e sublime a - Liberdade! (MONTEIRO, 1891, p. 130)

Nesse quadro, Julieta de Melo Monteiro manteve uma forte atuação como militante em prol do abolicionismo. Ela promoveu atividades artístico-culturais e outras ações para juntar 
verbas, cuja finalidade era a obtenção da manumissão de escravos, além de atuar decisivamente na organização de frentes emancipacionistas. Mesmo após a abolição, continuou as suas campanhas para debelar a pobreza, a qual atingia fortemente os negros, de modo que a sua atuação refletia também uma preocupação com a reinserção social dos libertos. Como intelectual, a escritora não deixou de lançar mão das suas criações textuais para combater o escravismo e promover a ideia da libertação definitiva dos escravos.

\section{A federalista}

No Rio Grande do Sul, o movimento republicano, sob a liderança de Júlio de Castilhos, assumiu uma feição positivista, autoritária e personalista. O maior projeto do castilhismo era a continuidade no poder, meta atingida, tendo em vista a permanência no governo de Castilhos, e depois de seu sucessor, Borges de Medeiros, por quase quatro décadas, de forma praticamente ininterrupta. O modelo castilhista era exclusivista, alijando do poder todos aqueles que não seguissem a cartilha de Castilhos, fenómeno que originou uma ferrenha oposição, formada por antigos liberais e conservadores e por várias levas de dissidentes republicanos. O castilhismo deixou marcas profundas na sociedade e na política rio-grandense, sobretudo pelas restrições impostas aos adversários, e ao caráter autoritário de suas práticas políticas (FRANCO, 2010, p. $57)$.

Impossibilitadas de chegar ao poder por meio das urnas a partir dos mecanismos criados pelos castilhistas (PESAVENTO, 1983, p. 71), as oposições apelaram para as armas, com a deflagração da Revolução Federalista (1893-1895), a qual marcou a conjuntura sulina com um clima de ódios, disputas e rivalidades que perduraram por toda a República Velha. A mais importante agremiação partidária que fez oposição ao regime castilhista foi o Partido Federalista, o qual não teve uma existência efémera, pois permaneceu em cena durante três décadas (LOVE, 1975, p. 53), movendo duradoura ação oposicionista (FRANCO, 2010, p. 8687). A tal agremiação partidária Julieta de Melo Monteiro se associou, exercendo um significativo papel, notadamente no âmbito rio-grandino. Como intelectual federalista, Julieta colocou-se na resistência, opondo-se frontalmente ao autoritarismo castilhista.

Uma das primeiras manifestações de Julieta Monteiro que mostrava algum tipo de desaprovação em relação ao regime vigente no Rio Grande do Sul deu-se por ocasião do falecimento de um jornalista liberal e que, após a república, fora perseguido por forças governistas até a sua morte. Em meio ao elogio fúnebre ao publicista, a escritora dizia que ele dera seu último suspiro trucidado por tantos sofrimentos, afirmando também que o mesmo morrera no seu "posto de honra”, lutando "denodadamente, como um bravo, como um herói, a 
peito descoberto". Para ela, tal morte abrira no jornalismo gaúcho um vácuo difícil de preencher, considerando aquele desaparecimento como uma "verdadeira catástrofe". $\mathrm{Na}$ concepção da escritora os "algozes" do escritor público não iriam atingir o seu objetivo de maneira completa, uma vez que a sua memória seria "inapagável”, tendo em vista o "precioso legado que o seu brilhantíssimo talento" trouxera para o Rio Grande do Sul (CORIMBO, Rio Grande, 15 jun. 1890, a. 6, n. 40, p. 1).

Outro personagem homenageado por Julieta foi o exilado imperador do Brasil, por ocasião do aniversário de seu falecimento. Enquanto elogiava D. Pedro II, a jornalista tecia apreciações negativas a respeito do regime vigente no Brasil desde 1889, lamentando todos aqueles anos de lutas e sofrimentos. De acordo com ela, parecia que a mão fria e pesada da fatalidade estendera-se sobre aquele tão desventurado, quanto outrora florescente país, depois da república imersa em guerra, sangue e destruição. Julieta Monteiro dizia que teria sido até preferível que o imperador tivesse desaparecido, pois, só assim, teria sido poupado da "grande dor de presenciar o esfacelamento da pátria", uma vez que, com a sua partida para o exílio, um "véu negro e tenebroso" cobrira as "opulentas terras do cruzeiro" (CORIMBO, Rio Grande, 3 dez. 1893, a. 10, n. 146, p. 1).

Em meio à Revolução Federalista, deflagração armada entre castilhistas e oposicionistas, a escritora pedia o fim da guerra, conclamando que se fizesse a paz no Rio Grande do Sul. Indiretamente, ela buscava demonstrar que a culpa do conflito bélico era dos adeptos do castilhismo, referindo-se a estes como "abutres ávidos de sangue e de carniça". Ela lamentava que o "ubérrimo solo gaúcho" estivesse servindo de esteira a um sem número de cadáveres insepultos que jaziam à mercê de "corvos famintos", por causa da "barbaridade dos homens". Julieta Monteiro exclamava que uma "fatalidade sem nome" e um "castigo imerecido" pesavam sobre a sua terra por causa de um "bando de aves de rapina" (CORIMBO, Rio Grande, 12 fev. 1894, a. 10, n. 154, p. 1).

As concepções político-ideológicas de Julieta ficavam ainda mais evidenciadas no artigo "Os heróis", no qual ela enaltecia a ação dos federalistas (CORIMBO, Rio Grande, 17 fev. 1894, a. 10, n. 155, p. 1). Na abertura do texto, com veemência e em manifestação carregada de ironia, a autora explicava a quem não caberia a categorização de herói, em clara alusão aos adversários castilhistas, que, segundo ela, não mereceriam ser heroificados:

Eu não classifico de heróis aqueles que marchando tão somente para obedecer às ordens de supremos mandões, vão sem calor, sem entusiasmo apresentar o peito às balas inimigas. 
Eu não desperdiço o expressivo epíteto, tão dificilmente colhido no ardor das pugnas, aplicando-o àqueles que, correndo atrás de conveniências próprias e principalmente de conveniências pecuniárias, procuram capacitar os pobres de espírito de que obram façanhas por amor à pátria.

Eu nunca lançarei palmas nem flores às plantas desses bravos que fazem estremecer a terra com o eco de seus triunfos, triunfos gloriosos colhidos em respeitosa distância do inimigo, porque, em presença dele, somem-se como que por encanto.

Eu nunca deixarei de ter um sorriso de desprezo, para esses heróis de pena ou espada, que, blasonando de independência de caráter, pureza de ideias, altivez nunca mentida, recebem sorrateiramente grosso subsídio, de mãos enluvadas e que empunham o bastão do governo, para sustentarem aquilo que muitas vezes não compreendem e estão longe, muito longe de discutir.

Para mim, essa classe de homens, só deve receber da sociedade honesta, sociedade dos homens que se prezam, o desprezo, a repugnância que inspiram os répteis.

Por outro lado, Julieta Monteiro, reconhecia claramente a imagem do herói na figura dos revolucionários que se batiam para buscar a derrubada do regime castilhista do poder:

Mas, eu serei sempre, sempre entusiasta fervorosa, adepta sincera, leal, daqueles que, diante dos sofrimentos da pátria, dos abusos, das arbitrariedades, dos crimes monstruosos, das ignominias que filhos desnaturados atiram-lhe às faces, esquecem tudo, amor de família, tranquilidade do lar, posição social, interesses públicos e particulares, para correrem em defesa dessa segunda mãe.

Esses sim, esses merecem o glorioso título de heróis.

Eles que não vacilam ante o perigo, que não tremem ante o feroz inimigo, que trocam as suas noites serenas e despreocupadas no abençoado seio da família, pela vigília, pelo sobressalto, pela marcha acelerada por ínvios caminhos.

Eles que, envoltos no manto do patriotismo, esquecem-se de si para pensar nos martírios de seus irmãos, no esfacelamento do seu torrão natal.

Eles que lutam com a fome, as intempéries do tempo, as mil vicissitudes de uma longa e penosa jornada, tendo sempre na mente a rosada missão do triunfo.

Eles que saltam barreiras quase insuperáveis, buscando afanosamente plantar na terra abençoada da pátria, o fulgurante lábaro da paz.

Eles que oferecem generosa e voluntariamente o seu ardoroso sangue em holocausto, são, ninguém ousará negá-lo, são os únicos, patriotas, os abnegados soldados da liberdade, os invencíveis heróis.

Ao opor-se ao regime ditatorial predominante, Julieta de Melo também lutou em nome da liberdade de expressão. O castilhismo por si só trazia consigo uma ditadura, cujo projeto essencial era a perpetuação no poder, por meio de políticas e práticas autoritárias e exclusivistas. A partir de tais fundamentos, houve uma tendência geral de repressão aos adversários, de modo que só os governistas poderiam usufruir da liberdade de imprensa. $\mathrm{O}$ aprofundamento da guerra civil levou a um cerceamento ainda mais drástico, havendo legislação federal que criava restrições praticamente absolutas ao jornalismo. Mesmo depois da pacificação, as rivalidades partidárias prosseguiram de modo que o modelo castilhista permaneceu em suas práticas persecutórias aos seus oposicionistas. 
Contra tais medidas restritivas à liberdade de imprensa houve significativas manifestações no contexto sul-rio-grandense, e a intelectualidade teve um papel importante como força contestatória e reivindicativa. Ainda que muitos intelectuais estivessem articulados e/ou cooptados em relação ao castilhismo, silenciando quanto ao cerceamento, alguns segmentos no seio desse universo intelectivo permaneceram independentes ou ainda colocaram-se em oposição àquele regime vigente. Uma das grandes bandeiras defendidas por esses grupos não vinculados ao poder foi a luta contra autoritarismo e a falta de liberdade, com a qual Julieta se identificou.

A partir de tal identidade, Julieta de Melo Monteiro não conseguia entender a existência e a ação plena do jornalismo sem que houvesse liberdade, de modo que se mostrou insatisfeita e combateu com ênfase o crescente processo de cerceamento à liberdade de expressão que se incrementou no Brasil na esfera federal e na estadual, após a mudança na forma de governo. Nessa linha, além de propugnar pela retomada da liberdade de imprensa, ela procurou denunciar casos de repressão e até violência que foram praticados contra o jornalismo no contexto sul-riograndense. Tal posicionamento, além das convicções federalistas, advinha da própria concepção da jornalista acerca do papel da imprensa, considerando que o jornalismo deveria promover uma cruzada toda de interesse público e utilidade instrutiva (O COMERCIAL, Rio Grande, 18-19 mar. 1878, a. 21, n. 65, p. 1).

Especificamente quanto aos atentados contra a imprensa, Julieta Monteiro publicou no Corimbo o artigo "Mais uma vítima". Segundo a publicista, nos "calamitosos tempos" que desgraçadamente atravessavam os gaúchos, não deveria causar estranheza a notícia de mais um assassinato, uma vez que tais crimes eram tantos e tão frequentes, que todos pareciam estar forçados a encará-los como acontecimentos naturais. Em tom de denúncia, a escritora observava que os homens de imprensa, principalmente, viviam ameaçados, e não poucos por amor à família - que dia e noite sobressaltada os aconselhava a silenciar sobre os insultos que lhes eram dirigidos -, passavam "por covardes aos olhos dos miseráveis" (CORIMBO, Rio Grande, a. 17 , n. 137,15 abr. 1900 , p. 3).

Em tal matéria, a jornalista narrava que, na cidade sul-rio-grandense de Uruguaiana, acabara de tombar "vitimado por infames assassinos mais um distinto colega", diretor de periódico local. Diante do ocorrido, a articulista perguntava qual teria sido o crime do "inditoso jornalista", respondendo se seria o de ter uma ideia e sustentá-la, não se curvando aos "mandões da terra", não vendendo a sua pena, não se humilhando para receber a proteção "dos grandes, dos poderosos, dos senhores da situação". Com base em tais constatações, ela lamentava, 
exclamando "Pobre Rio Grande". Mantendo o teor de contestação, a autora se referia ao "altivo e ousado berço do valoroso gaúcho" e questionava ao que fora reduzido o estado, o que teriam feito da sua liberdade e a que ponto quereriam levar os seus legendários filhos. Perante tais questões, Julieta concluía em tom exortativo, afirmando: "Dez anos de lutas, dez anos de sofrimentos, dez anos a esperar o dia de amanhã, esse dia que não surge, porque o amanhã é cada vez mais tenebroso!” (CORIMBO, Rio Grande, a. 17, n. 137, 15 abr. 1900, p. 3).

Nesse sentido, a escritora participou ativamente do confronto discursivo entre castilhistas e federalistas, adotando o lado destes e criticando com acidez a ação daqueles. Em sua militância, a autora lançou vários textos panegíricos, com homenagens a lideranças federalistas, levando em frente o combate aos governistas na esfera estadual e federal. Desse modo, em termos políticos, Julieta Monteiro resistiu e opôs-se ao castilhismo e, em tal ação, ao passo que a maior parte dos intelectuais anticastilhistas utilizou a prática de vociferar contra as lideranças republicanas e seus sectários, ela adotou um estilo diferenciado e mesmo um refinamento. Embora também chegasse a incorrer com veemência em tons exclamativos e exortativos, ela tecia as críticas aos adversários sem lhes citar os nomes, lançando mão de recursos discursivos como a ironia para atacá-los. Por outro lado, não poupou esforços para elogiar a ação e honrar a memória dos líderes federalistas, visando a demarcar o papel de tal agremiação como digna representante da liberdade dos sul-rio-grandenses.

Assim, Julieta de Melo Monteiro desenvolveu, ao lado de sua carreira literária, uma veemente ação de militante. Foi ardorosa defensora de causas pelas quais redigiu editoriais, artigos, poemas, crónicas e polémicas na defesa dessas bandeiras. Um ponto essencial das suas lutas foi pela igualdade e emancipação feminina, de modo que, sem cansar, dedicou sua vida ao aprimoramento da educação das jovens e à busca de novas formas de inserção da mulher na sociedade. Ao lado dessa incansável batalha, foi também uma libertária de primeira ordem. Nesse sentido, combateu a enraizada instituição escravocrata, batendo-se firmemente, por meio de suas composições textuais e ações práticas, em nome do ideal abolicionista. Mas também pregou a liberdade para os sul-rio-grandenses, combatendo a opressão da ditadura castilhista, filiando-se num partido oposicionista e movendo figadal campanha de resistência. Os seus textos em prosa e verso, publicados junto ao jornalismo e por meio de livros, expressaram uma das tantas facetas da escrita feminina no Brasil Meridional, vinculada ao engajamento pela liberdade, fosse aquela associada aos direitos da mulher, à emancipação dos cativos ou à oposição a um duradouro regime ditatorial. Em tudo condizente com o perfil de rara beleza que 
é conferido a quem luta com coragem pelo que acredita, sem ressentimentos por ter de deixar outras facetas porventura menos cuidadas.

Afinal, publicista, Julieta tornou-se, até hoje, arauto da liberdade e a sua estatura transcendeu a de um qualquer busto, trabalhado com cinzel na madeira, ferro, bronze, pedra, ou em tela que lhe tivesse sido dedicado.

\section{Referências}

BOURDIEU, Pierre. As regras da arte: gênese e estrutura do campo literário. São Paulo: Companhia das Letras, 1996.

BOURDIEU, Pierre. A influência do jornalismo. In: Sobre a televisão. Rio de Janeiro: Jorge Zahar, 1997. p. 99-120.

BOURDIEU, Pierre. A economia das trocas simbólicas. 6. ed. São Paulo: Perspectiva, 2007.

BRANCO, Lúcia Castello. A escrita mulher. In: BRANCO, Lúcia Castello \& BRANDÃO, Ruth Silviano. A mulher escrita. Rio de Janeiro: Casa-Maria Editorial; Livros Técnicos e científicos, 1989. p. 85-172.

BRANCO, Lúcia Castelo. O que é escrita feminina. São Paulo: Brasiliense, 1991.

CARDOSO, Fernando Henrique. Capitalismo e escravidão no Brasil Meridional. 3. ed. Rio de Janeiro: Paz e Terra, 1991.

COELHO, Nelly Novaes. Dicionário crítico de escritoras brasileiras. São Paulo: Escrituras Editora, 2002.

COSTA, Emilia Viotti da. A abolição. 4. ed. São Paulo: Global, 1988.

FLORES, Hilda Agnes Hübner. Dicionário de mulheres. Porto Alegre: Nova Dimensão, 1999.

FRANCO, Sérgio da Costa. Dicionário político do Rio Grande do Sul (1821-1937). Porto Alegre: Suliani Letras \& Vida, 2010.

LOVE, Joseph L. O regionalismo gaúcho. São Paulo: Perspectiva, 1975.

MAGALHÃES, Isabel Allegro de. O sexo dos textos e outras leituras. Lisboa: Editorial Caminho, 1995.

MAGALHÃES, Isabel Allegro de. Diferenças sexuais na escrita: ao contrário de Diotima. In: Actas do Colóquio "Escrita de mulheres". Coimbra: Faculdade de Letras - Universidade de Coimbra, 2005. p. 9-23.

MINGOCHO, Maria Teresa Delgado. Nota prévia. In: Actas do Colóquio "Escrita de mulheres”. Coimbra: Faculdade de Letras - Universidade de Coimbra, 2005. p. 7-8. 
MONTEIRO, Julieta de Melo. Oscilantes. Pelotas: Livraria Universal, 1891.

PEIXINHO, Ana Teresa. Escritores e jornalistas: um estudo de caso. In: RIBEIRO, Maria Manuela Tavares (coord.). Outros combates pela História. Coimbra: Imprensa da Universidade de Coimbra, 2010. p. 423-436.

PESAVENTO, Sandra Jatahy. A Revolução Federalista. São Paulo: Brasiliense, 1983.

QUEIROZ, Suely R. Reis de. A abolição da escravidão. São Paulo: Brasiliense, 1981.

RÜDIGER, Francisco Ricardo. Tendências do jornalismo. Porto Alegre: Ed. da UFRGS, 1993.

SCHMIDT, Rita Terezinha. Julieta de Melo Monteiro. In: MUZART, Zahidé Lupinacci (org.). Escritoras brasileiras do século XIX. 2. ed. Florianópolis: Editora Mulheres; Santa Cruz do Sul: EDUNISC, 2000. p. 306-319.

SCHUMAHER, Schuma \& BRAZIL, Érico Vital. Dicionário de mulheres do Brasil: de 1500 até a atualidade. 2. ed. Rio de Janeiro: Zahar, 2000.

SOARES, Pedro Maia. Feminismo no Rio Grande do Sul - primeiros apontamentos (18351945). In: BRUSCHINI, Maria Cristina \& ROSEMBERG, Fúlvia (orgs.). Vivência: história, sexualidade e imagens femininas. São Paulo: Fundação Carlos Chagas; Brasiliense, 1980. p. 121-150.

SODRÉ, Nelson Werneck. A história da imprensa no Brasil. Rio de Janeiro: Civilização Brasileira, 1966. 